\title{
Effect of Dietary Macronutrients on Postprandial Glucagon and Insulin Release in Obese and Normal-Weight Women
}

\author{
Tomasz Wikarek, ${ }^{1,2}$ Piotr Kocelak (D), ${ }^{1}$ Aleksander J. Owczarek ${ }^{(D)},{ }^{3}$ Jerzy Chudek $\left(\mathbb{D},{ }^{4,5}\right.$ \\ and Magdalena Olszanecka-Glinianowicz $\mathbb{D}^{1}$ \\ ${ }^{1}$ Health Promotion and Obesity Management Unit, Department of Pathophysiology, Medical Faculty in Katowice, \\ The Medical University of Silesia, Katowice, Poland \\ ${ }^{2}$ Department of Gynecology and Obstetrics, Medical Faculty in Katowice, The Medical University of Silesia, Katowice, Poland \\ ${ }^{3}$ Department of Statistics, Faculty of Pharmaceutical Sciences in Sosnowiec, Medical University of Silesia, \\ Katowice, Poland \\ ${ }^{4}$ Pathophysiology Unit, Department of Pathophysiology, Medical Faculty in Katowice, The Medical University of Silesia, \\ Katowice, Poland \\ ${ }^{5}$ Department of Internal Medicine and Oncological Chemotherapy, Medical Faculty in Katowice, \\ The Medical University of Silesia, Katowice, Poland
}

Correspondence should be addressed to Magdalena Olszanecka-Glinianowicz; magolsza@gmail.com

Received 24 November 2019; Revised 10 March 2020; Accepted 30 March 2020; Published 30 April 2020

Academic Editor: Andrea Palermo

Copyright (c) 2020 Tomasz Wikarek et al. This is an open access article distributed under the Creative Commons Attribution License, which permits unrestricted use, distribution, and reproduction in any medium, provided the original work is properly cited.

The aim of the study was to assess the effect of dietary macronutrients on circulating glucagon and insulin levels in obese and normal-weight women. Potentially, the impaired release of glucagon may proceed abnormal glucose metabolism in obese patients ahead of overt diabetes. In 20 insulin-sensitive women (11 obese and 9 normal-weight), plasma concentrations of insulin and glucagon levels were assessed before and after 3 different macronutrient test meals. $\mathrm{AUC}_{\text {total }}$ insulin in the obese group was increased after protein and carbohydrates compared to fatty test meal consumption (3981 \pm 2171 and $4869 \pm 2784$ vs. $2349 \pm 1004 \mu \mathrm{IU} * \mathrm{~h} / \mathrm{m}, p<0.05$, respectively), but without a difference between protein and carbohydrates ingestion. However, in the normal-weight group, $\mathrm{AUC}_{\text {total }}$ insulin was increased after carbohydrates compared to fatty test meal ingestion $(3929 \pm 1719$ vs. $2231 \pm 509 \mu \mathrm{IU} * \mathrm{~h} / \mathrm{ml}, p<0.05)$ and similar after carbohydrate and protein as well as after fatty and protein test meals $\left(3929 \pm 1719\right.$ vs. $2231 \pm 509$ vs. $3046 \pm 1406 \mu \mathrm{IU} * \mathrm{~h} / \mathrm{ml}$, respectively). However, AUC $_{\text {total }}$ insulin was significantly increased in obese compared to normal-weight women only after carbohydrate test meal ingestion $(4869 \pm 2784 \mathrm{vs} .3929 \pm 1719 \mu \mathrm{IU} * \mathrm{~h} / \mathrm{ml}$,

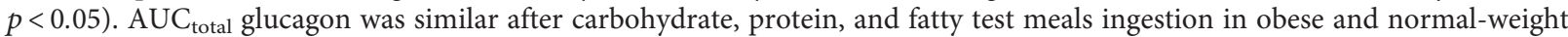
women $(921 \pm 356$ vs. $957 \pm 368$ vs. $926 \pm 262 \mathrm{ng} * \mathrm{~h} / \mathrm{ml}$ and $1196 \pm 14$ vs. $1360 \pm 662$ vs. $1792 \pm 1176 \mathrm{ng} * \mathrm{~h} / \mathrm{ml}$, respectively). $\mathrm{AUC}_{\text {total }}$ glucagon was significantly lower in obese than normal-weight women after a fatty meal $(926 \pm 262 \mathrm{vs} .1792 \pm 1176 \mathrm{ng} * \mathrm{~h} /$ $\mathrm{ml}, p<0.01$ ). Postprandial glucagon secretion is not related to the macronutrient composition of the meal in normal-weight women since postprandial glucagon concentrations were stable and did not change after carbohydrate, protein, and fatty test meals. Lower glucagon secretion was observed in obese subjects after fatty meal consumption when compared to normal-weight subjects. Postprandial insulin profile was significantly higher after carbohydrate than fatty test meal intake in the obese group and did not differ between obese and normal-weight groups after carbohydrate, protein, and fatty test meals consumption. Impaired glucagon secretion after fatty meat suggests early pancreatic alpha-cell dysfunction, after a carbohydrate meal is a compensatory mechanism. 


\section{Introduction}

Glucagon is a 29-amino-acid peptide released by the pancreatic $\alpha$ cells with an antagonistic action to insulin, which has a hyperglycemic effect by enhancement of gluconeogenesis and glycogenolysis in the liver [1].

Physiologically, the serum concentration of glucagon is the highest in the morning, in a fasting state, and decreases postprandially. The stimulants for glucagon release are amino acids, catecholamines, corticosteroids, and intestinal hormones including cholecystokinin, gastrin, and GIP, as well as adrenergic activation in hypoglycemia, whereas glucose and free fatty acids inhibit its release [1].

Insulin, an opponent pancreatic hormone, participating in the regulation of glucose homeostasis, is mainly secreted by the beta cells stimulated by incretin hormones (GLP1-glucagon-like peptide-1 and GIP-glucose-dependent insulinotropic polypeptide) released by enteroendocrine cells of the gut in response to nutrient absorption [2, 3]. The phenomenon of greater stimulation of insulin release after an oral glucose load than intravenous glucose infusion is called the incretin effect [2].

Meal volume and its composition, including the composition of amino acids, determine glucagon release postprandially. The main place of glucagon action is the liver. However, its receptors have been also identified in the pancreatic $\beta$ cells, heart, kidneys, brain, intestine, adrenal glands, vessels, and adipose tissue [4].

Interestingly, incretin hormones modulate also glucagon secretion. GLP-1 suppresses its secretion, especially in a hyperglycemic state [5], whereas GIP was found to stimulate glucagon secretion [6] to more extent with lower glucose concentration. Moreover, intravenous glucose infusion suppresses glucagon secretion more than oral glucose load at least in healthy subjects $[7,8]$.

One of the important glucagon actions is the regulation of body mass homeostasis by the impact on satiety sensation and consumed meal size, shown in both rats and humans $[1,9-11]$. It seems that glucagon exerts its action on satiety centrally by inhibiting ghrelin action, depending on the consumed meal size [12, 13]. Ghrelin stimulates neuropeptide $\mathrm{Y}$ and agouti-related protein release and in consequence decreases satiety and increases hunger [14-16]. It is suggested that impaired effect of glucagon on satiety may be important in diabetic and obese subjects, contributing to the further increase of body fat accumulation due to the altered sensation of postprandial satiety and enhanced food intake. However, more recent data showed that glucagon-induced satiety is preserved in type 1 diabetic patients but lowered in obese regardless of insulin release [13]. The role of glucagon in the development of diabetes is widely accepted and supported by many studies that showed its role in the regulation of body mass and energy expenditure by its central action on food intake. Moreover, some new data showed a potential role of glucagon receptor antagonists in the management of obesity and diabetes [17, 18]. Higher fasting plasma glucagon levels and the lack of its postprandial suppression or even enhanced secretion were shown in subjects with type 2 diabetes [19]. One study found differences in glucagon release in diabetic obese and normalweight subjects after a mixed test meal intake. Higher fasting glucagon concentration and postprandial glucagon release were observed in obese than in nonobese diabetic subjects. Besides, a significant positive correlation between fasting glucagon levels and BMI in normal-weight and obese diabetic subjects was shown [20].

Previous studies have reported diminished incretin effect in obesity even in the lack of abnormal glucose metabolism [21] due to a reduced release of GLP-1 after nutrient ingestion [22] and reduced responsiveness to GIP, since higher postprandial GIP concentration was detected in obesity which potentially may stimulate hunger [23].

In our previous study, we analyzed postprandial glucagon-like peptide-1 (GLP-1) and glucose-dependent insulinotropic polypeptide (GIP), but not glucagon release [24] after ingestion of different types of meals as potentially different macronutrients may attenuate not only insulin release but also a sensation of satiety and hunger.

The abnormal release of gut hormones is observed in type 2 diabetes; however, this abnormality may proceed with the development of diabetes and be the first sign of the development of hyperglycemia. It seems that abnormal glucagon release may also occur in obese subjects ahead of the development of type 2 diabetes.

Therefore, the present study aimed to assess the effect of dietary macronutrients on postprandial glucagon and insulin release in obese and normal-weight nondiabetic young women.

\section{Materials and Methods}

2.1. Experimental Methods. The study included eleven obese and nine healthy normal-weight subjects as described in detail previously [24]. The protocol of inclusion and exclusion criteria was similar to the protocol presented in the previous paper [24].

The characteristics of the study groups are presented in Table 1.

2.2. Study Protocol. All the subjects were served carbohydrate, protein, and fatty test meals. The procedure and content of the test meals were described previously [24].

All the procedures were approved by the Bioethical Committee. All the study participants gave their informed consent before enrollment into the study.

2.3. Laboratory Procedures. Venous blood samples were collected for biochemical measurements in the manner described previously [24]. Besides, plasma glucagon was assessed by EIA (Phoenix Pharmaceuticals, Inc., US) with a lower limit of sensitivity of $0.28 \mathrm{ng} / \mathrm{ml}$, respectively, and intra- and interassay CV of 5.0-10.0 and $<15 \%$, respectively.

2.4. Statistical Analysis. All statistical analyses were previously described in detail [24]. The $p$ value less than 0.05 was 
TABLE 1: Characteristics of the study groups (mean values and standard deviations).

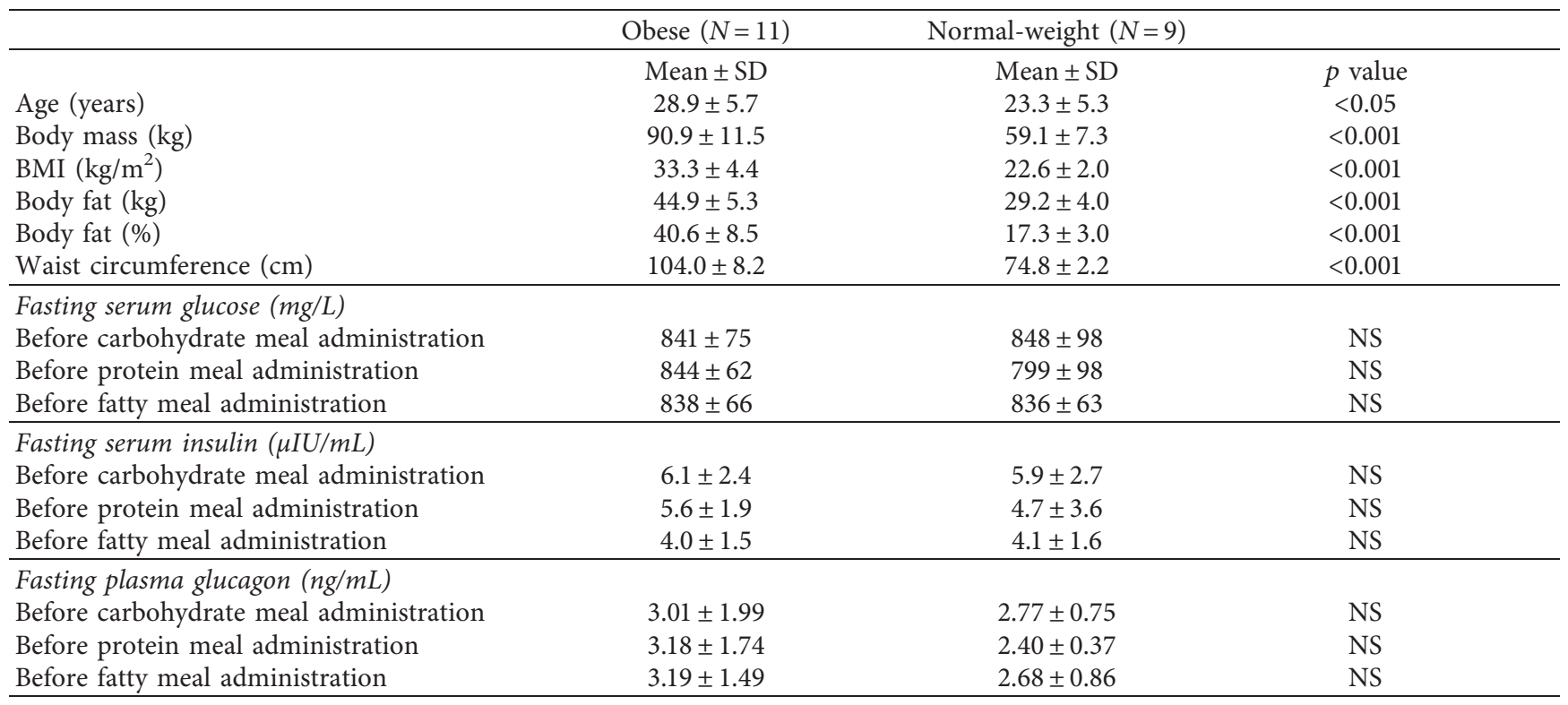

set as statistically significant. The power $(\beta)$ of all tests are assured to be not less than $70 \%$.

\section{Results}

3.1. Changes in Plasma Glucagon Concentrations after Test Meals. Fasting plasma glucagon levels did not differ before ingestion of all the test meals and the consumption of the meals did not change its concentration in both study groups (Table 1).

Postprandial glucagon concentrations did not change after ingestion of carbohydrate and protein test meals when compared to fasting concentrations in the study and control groups. There were also no differences in their concentrations after carbohydrate and protein meals between study and control groups, while postprandial glucagon levels were significantly higher after fatty meal ingestion in normalweight than in the obese group $(p<0.05)$ (Figure 1).

There were no differences in postprandial AUC plasma glucagon concentrations between carbohydrate and protein in relation to a fatty meal and after carbohydrate and protein meals consumption in both the study and control groups. Only after fatty meal consumption, postprandial AUC glucagon concentration was significantly higher in normalweight than in the obese group $(p<0.01)$ (Table 2; Figure 1).

The mean time to peak glucagon concentration after fatty test meal was $172 \pm 48$ minutes in the normal-weight group. However, it was not possible to determine peak glucagon concentration in the obese group due to a flat postprandial profile.

There was no correlation between peak plasma glucagon concentration and maximum satiety sensation as well as minimum hunger sensation after fatty meal consumption in the control group.

The estimated return time of plasma glucagon to fasting concentration based on the approximation function $\left(y=A_{1} * t^{4}+A_{2} * t^{3}+A_{3} * t^{2}+A_{4} * t+A_{5}\right)$, where $A_{i}$ is a value of glucagon/insulin in the $i$-th time point of measurement and $t$ is time, and it was $6 \mathrm{~h}$ in the control group and $9 \mathrm{~h} 52 \mathrm{~min}$ in the study group. The goodness of fit was very good with $R^{2}=0.994$.

3.2. Changes in Plasma Insulin Concentrations after Test Meals. There were no differences in fasting insulin concentrations before test meals administration within the obese and control groups and between groups. However, its level was significantly higher in the obese group, but not in the normal-weight group, before consumption of the carbohydrate than the fatty test meal intake (Table 1).

Postprandial insulin profile did not differ between both groups after all test meals consumption. However, postprandial insulin profile was significantly higher after carbohydrate than fatty test meal intake, but only in the obese group $(p<0.01)$ (Figure 1$)$.

The AUC of total insulin value was higher after the protein and carbohydrate than the fatty test meal intake $(p<0.05)$ in the obese group and did not differ after ingestion of the protein and carbohydrate test meals, while in the normal-weight group, the AUC of total insulin value was higher only after the carbohydrate than the fatty test meal intake $(p<0.05)$ and did not differ after the carbohydrate and protein test meals as well as the protein and fatty test meals intake. The AUC of total insulin value was significantly higher in obese women than in normal-weight women only after the carbohydrate test meal intake $(p<0.05)$ (Table 2).

Time to maximum postprandial serum insulin concentration was similar after carbohydrate and protein test meals intake in obese and normal-weight groups (61 $\pm 47 v s$. $34 \pm 16 \mathrm{~min}$ and $46 \pm 19$ vs. $32 \pm 16 \mathrm{~min}$, respectively).

Based on a linear regression model analysis, there were no differences in the estimated time to return to fasting insulin concentrations after protein and carbohydrate test 

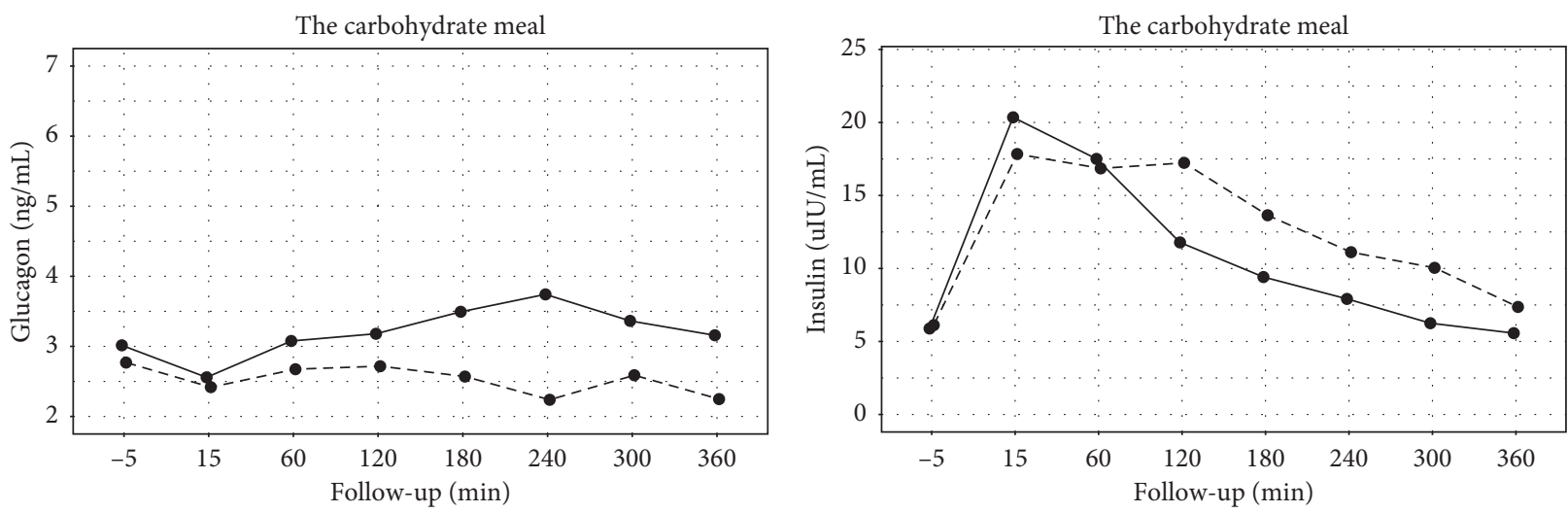

Group

_ Control group

- - - Obese group

Group

- Control group

- - - Obese group

(a)

(b)
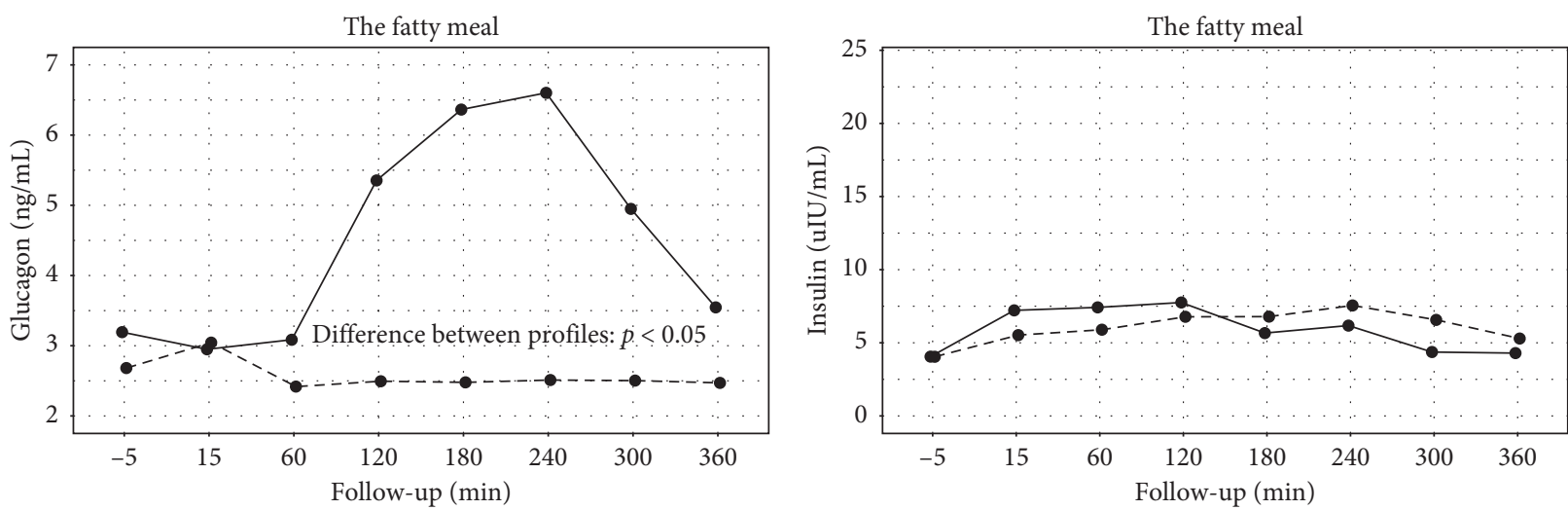

Group

- Control group

Group

_ Control group

- - - Obese group

(c)

(d)
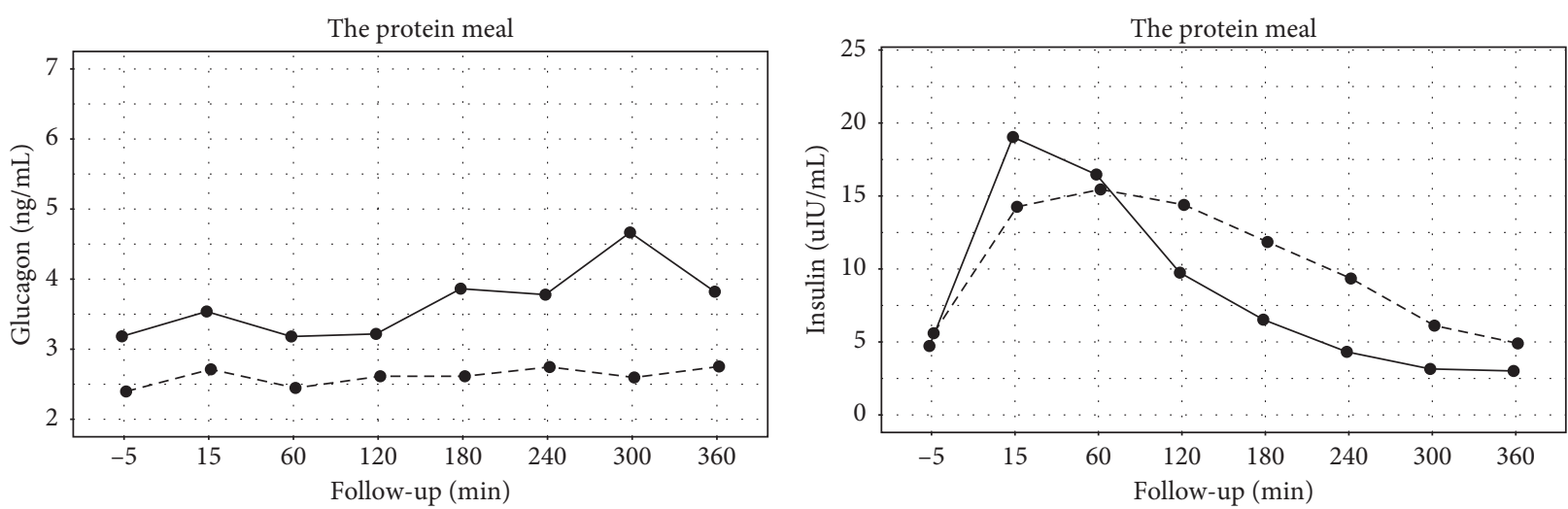

Group

_ Control group

Group

_ Control group

- - - Obese group

(e)

(f)

Figure 1: Plasma glucagon concentrations before and during a $6 \mathrm{~h}$ period after consumption of the test meals. Carbohydrate meal: (a) glucagon and (b) insulin levels. Fatty meal: (c) glucagon and (d) insulin levels. Protein meal: (e) glucagon and (f) insulin levels. 
TABLE 2: Effect of the test meals on insulin and glucagon release (AUC value) in obese $(N=11)$ and normal-weight $(N=9)$ subjects (mean values and standard deviations).

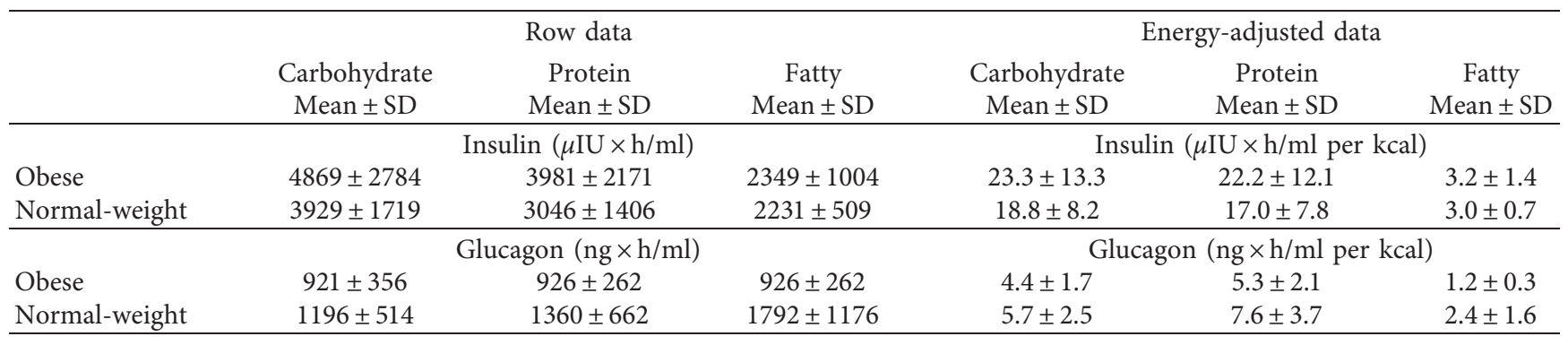

meals intake in both groups. There were also no differences in estimated time between the obese and normal-weight groups after carbohydrate and protein test meals intake $(10 \mathrm{~h}$ and $10 \mathrm{~min} v s .7 \mathrm{~h}$ and $24 \mathrm{~min} ; 8 \mathrm{~h}$ and $43 \mathrm{~min}$ vs. $6 \mathrm{~h}$ and 4 min, respectively).

There were no correlations between anthropometric parameters and $\log _{10}$ of fasting and AUC of glucagon concentrations after carbohydrate and protein test meals intake. The $\log _{10}$ of postprandial glucagon concentrations was inversely proportional to BMI and fat mass $(r=-0.60$, $p<0.01$, and $r=-0.57, p<0.01$, respectively, and $r=-0.62$, $p<0.01$, and $r=-0.60, p<0.01$, respectively) after fatty test meal intake.

In the obese group, there were positive correlations between AUC of postprandial glucagon concentration and plasma insulin concentrations $(r=0.62, p<0.05$, respectively) after a fatty meal.

\section{Discussion}

In our previous study [24]) the protocol of the study was similar as in the present study. Three different solid meals were given to all the subjects, which consisted of $93 \%$ energy of carbohydrate, $72 \%$ energy of protein, and $84 \%$ energy of fat in a sequence parallel with visual scoring of satiety sensation. The results of the study [24] showed that the reduced GLP-1 release after consumption of a fatty meal in obese women may explain the impaired sensation of satiety, and the impaired postprandial GIP release may be the early indicator of incretin axis dysfunction in obese women.

Our study shows similar fasting glucagon levels in obese and normal-weight women, but flat glucagon postprandial profile in the obese group, and significantly lower postprandial glucagon levels after fatty test meal intake in obese may represent an adaptive mechanism preventing an increase in postprandial glucose concentration in the early stage of insulin resistance without compensative hyperinsulinemia.

Fasting plasma glucagon levels were similar before ingestion of all the test meals in both study groups and did not differ between the obese and normal-weight women. In addition, we observed no postprandial differences in glucagon levels, as well as its postprandial AUC after carbohydrate and protein meals intake between the obese and normal-weight groups, and only after fatty meal intake glucagon levels and its postprandial AUC were lower in obese than normal-weight women. Moreover, our results showed that $\log _{10}$ of AUC of postprandial glucagon concentration after fatty meal intake was inversely proportional to BMI and fat mass. It should be noted that a previously published study showed divergent results. In this study, postprandial glucagon levels were higher after fatty meal consumption in obese than normal-weight women [25]. However, our previously published study showed that postprandial incretin axis dysregulation precedes insulin resistance and hyperinsulinemia development in obese. It suggests that lower postprandial GIP levels may prevent enhanced glucagon secretion in the early stage of insulin resistance [24]. This hypothesis is confirmed by the results of studies that showed that GIP is the main stimulus for glucagon release in type 2 diabetic subjects [26]. Moreover, physiologically GLP-1 is a glucagon-release inhibitor [27].

The return time of plasma glucagon to fasting concentration could only be estimated in normal-weight subjects after high-fat meal consumption, whereas in obese, it was not possible to estimate the time as a flat course of postprandial glucagon concentration was observed irrespective of meal composition. It may be explained partially as the mechanism delaying the occurrence of postprandial hyperglycemia in insulin-resistant subjects with subsequent hyperinsulinemia. In a study on the influence of liquid high-protein meal (510 kcal, of which 180 from soy protein), the peak time for glucagon concentration was 35 minutes regardless of BMI and age. In that study, it was shown that liquid protein meal was stimulating glucagon secretion proportionally to its protein content but independently from BMI [28]. No differences were observed in postprandial AUC of plasma glucagon concentrations after test meals consumption in both study and control groups, irrespective of BMI and higher fasting and postprandial glucagon concentrations observed in men; however, the influence of sex on glucagon is not well established as some investigators showed higher insulin-induced concentrations in men with comparable fasting levels suggesting enhanced counterregulatory effects [28-31], whereas others found no differences in fasting and exercise [32] or hypoglycaemia-induced glucagon concentrations [33]. As mentioned above, in our study, there were no differences in AUC of postprandial glucagon concentrations after test meals in both study groups. The divergent results may stem from a small study cohort and their heterogeneity with the 
presence of insulin resistance in studied subjects, as well as mixed macronutrient content of test meals.

It is worth to mention that fatty meal was the greatest stimulator of glucagon secretion in normal-weight subjects. An interesting finding shown in our study is that the $\log _{10}$ of postprandial glucagon concentrations was inversely proportional to BMI and fat mass after fatty test meal intake. In contrast, in a study performed in diabetic subjects, a positive correlation between fasting glucagon concentration and BMI and higher fasting glucagon level and postprandial AUC in obese than nonobese diabetics were showed [20].

Even though no differences were shown for AUC postprandial insulin concentrations, the result of previously published study [34] showed that high carbohydrate meal stimulates an early phase of glucagon secretion and high-fat meals induce a late phase of glucagon release. It seems that lower postprandial glucagon concentration in obese women after a fat meal in our study may be an early sign of pancreatic alpha-cell dysfunction, or it may represent a counterregulatory mechanism to the development of insulin resistance. This hypothesis is supported by positive correlations between the AUC of postprandial glucagon concentration and plasma insulin concentrations after a fatty meal in the obese group.

An interesting result obtained in our study is longer estimated return time of plasma glucagon to fasting concentration in obese than the normal-weight group. It suggests the next step of disturbances in postprandial glucagon release. However, further studies are necessary to confirm this observation.

4.1. Limitation of the Study. The limitation of this study is the small sample size and only female participants enrolled for better heterogeneity. Moreover, test meals energy content and density were divergent and we did not evaluate with high-fibre test meal. We did not measure daily energy consumption and content throughout the examination as well as the kinetics of gastric emptying. Furthermore, test meals were not administered randomly.

\section{Conclusion}

Postprandial glucagon secretion is not related to the macronutrient composition of the meal in normal-weight women since postprandial glucagon concentrations were stable and did not change after carbohydrate, protein, and fatty test meals.

Lower glucagon secretion was observed in obese subjects after fatty meal consumption when compared to normalweight subjects.

Postprandial insulin profile was significantly higher after carbohydrate than fatty test meal intake in the obese group.

Postprandial insulin secretion did not differ between obese and normal-weight groups after carbohydrate, protein, and fatty test meals consumption.

Impaired glucagon secretion after fatty meat suggests early pancreatic alpha-cell dysfunction, while higher insulin secretion after a carbohydrate meal is a compensatory mechanism for developing insulin resistance in obese subjects.

\section{Data Availability}

Database is stored by statistitian and available on reasonable request.

\section{Disclosure}

The manuscript was presented as a poster in the $20^{\text {th }} \mathrm{Eu}-$ ropean Congress on Obesity in 2013, in section T1:PS1Genetics, Epigenetics, Omics. The funder had no role in the design, analysis, or writing of the article.

\section{Conflicts of Interest}

The authors declare that there are no conflicts of interest regarding the publication of this paper.

\section{Authors' Contributions}

TW conducted the experiment and collected the data; PK wrote the manuscript; JC was involved in data analyses and helped in the drafting of the manuscript; AO participated in the design of the study and performed the statistical analysis; MOG conceived the study, participated in its design and coordination, and helped in the drafting of the manuscript. All authors read and approved the final manuscript.

\section{Acknowledgments}

The study was funded by the National Science Center (project no. 4566-B/P01/201039) and Medical University of Silesia grant KNW-1170K90.

\section{References}

[1] N. Geary, L. Asarian, and W. Langhans, "The satiating potency of hepatic portal glucagon in rats and insulin or insulin antibodies," Physiology \& Behavior, vol. 61, no. 2, pp. 199-208, 1997.

[2] M. A. Nauck and J. J. Meier, "The incretin effect in healthy individuals and those with type 2 diabetes: physiology, pathophysiology, and response to therapeutic interventions," The Lancet Diabetes \& Endocrinology, vol. 4, no. 6, pp. 525536, 2016.

[3] W. Creutzfeldt, "The incretin concept today," Diabetologia, vol. 16, no. 2, pp. 75-85, 1979.

[4] J. Christophe, "Glucagon and its receptor in various tissues," Annals of the New York Academy of Sciences, vol. 805, no. 805, pp. 31-33, 1996.

[5] M. A. Nauck, M. M. Heimesaat, C. Orskov, J. J. Holst, R. Ebert, and W. Creutzfeldt, "Preserved incretin activity of glucagon-like peptide 1 [7-36 amide] but not of synthetic human gastric inhibitory polypeptide in patients with type- 2 diabetes mellitus," Journal of Clinical Investigation, vol. 91, no. 1, pp. 301-307, 1993.

[6] J. J. Meier, B. Gallwitz, N. Siepmann et al., "Gastric inhibitory polypeptide (GIP) dose-dependently stimulates glucagon secretion in healthy human subjects at euglycaemia," Diabetologia, vol. 46, no. 6, pp. 798-801, 2003. 
[7] F. K. Knop, T. Vilsbøll, S. Madsbad, J. J. Holst, and T. Krarup, "Inappropriate suppression of glucagon during OGTT but not during isoglycaemic i.v. glucose infusion contributes to the reduced incretin effect in type 2 diabetes mellitus," Diabetologia, vol. 50, no. 4, pp. 797-805, 2007.

[8] J. J. Meier, C. F. Deacon, W. E. Schmidt, J. J. Holst, and M. A. Nauck, "Suppression of glucagon secretion is lower after oral glucose administration than during intravenous glucose administration in human subjects," Diabetologia, vol. 50, no. 4, pp. 806-813, 2007.

[9] N. Geary, "Pancreatic glucagon signals postprandial satiety," Neuroscience \& Biobehavioral Reviews, vol. 14, no. 3, pp. 323-338, 1990.

[10] J. Le Sauter, U. Noh, and N. Geary, "Hepatic portal infusion of glucagon antibodies increases spontaneous meal size in rats," American Journal of Physiology-Regulatory, Integrative and Comparative Physiology, vol. 261, no. 1, pp. R162-R165, 1991.

[11] N. Geary, H. R. Kissileff, F. X. Pi-Sunyer, and V. Hinton, "Individual, but not simultaneous, glucagon and cholecystokinin infusions inhibit feeding in men," American Journal of Physiology-Regulatory, Integrative and Comparative Physiology, vol. 262, no. 6, pp. R975-R980, 1992.

[12] M. A. Arafat, B. Otto, H. Rochlitz et al., "Glucagon inhibits ghrelin secretion in humans," European Journal of Endocrinology, vol. 153, no. 3, pp. 397-402, 2005.

[13] A. M. Arafat, M. O. Weickert, A. Adamidou et al., "The impact of insulin-independent, glucagon-induced suppression of total ghrelin on satiety in obesity and type 1 diabetes mellitus," The Journal of Clinical Endocrinology \& Metabolism, vol. 98, no. 10, pp. 4133-4142, 2013.

[14] S.-C. Lu, J. Xu, N. Chinookoswong et al., "An acyl-ghrelinspecific neutralizing antibody inhibits the acute ghrelin-mediated orexigenic effects in mice," Molecular Pharmacology, vol. 75, no. 4, pp. 901-907, 2009.

[15] C. Anderwald, G. Brabant, E. Bernroider et al., "Insulin-dependent modulation of plasma ghrelin and leptin concentrations is less pronounced in type 2 diabetic patients," Diabetes, vol. 52, no. 7, pp. 1792-1798, 2003.

[16] Q. Tong, C.-P. Ye, J. E. Jones, J. K. Elmquist, and B. B. Lowell, "Synaptic release of GABA by AgRP neurons is required for normal regulation of energy balance," Nature Neuroscience, vol. 11, no. 9, pp. 998-1000, 2008.

[17] B. Ahrén, "Glucagon-early breakthroughs and recent discoveries," Peptides, vol. 67, pp. 74-81, 2015.

[18] P. Shah, A. Vella, A. Basu, R. Basu, W. F. Schwenk, and R. A. Rizza, "Lack of suppression of glucagon contributes to postprandial hyperglycemia in subjects with type 2 diabetes Mellitus1," The Journal of Clinical Endocrinology \& Metabolism, vol. 85, no. 11, pp. 4053-4059, 2000.

[19] R. H. Unger and L. Orci, "Glucagon and the a cell," New England Journal of Medicine, vol. 304, no. 26, pp. 1575-1580, 1981.

[20] J. Kozawa, K. Okita, H. Iwahashi, K. Yamagata, A. Imagawa, and I. Shimomura, "Early postprandial glucagon surge affects postprandial glucose levels in obese and non-obese patients with type 2 diabetes," Endocrine Journal, vol. 60, no. 6, pp. 813-818, 2013.

[21] E. Muscelli, A. Mari, A. Casolaro et al., "Separate impact of obesity and glucose tolerance on the incretin effect in normal subjects and type 2 diabetic patients," Diabetes, vol. 57 , no. 5 , pp. 1340-1348, 2008.

[22] K. Faerch, S. S. Torekov, D. Vistisen et al., "GLP-1 response to oral glucose is reduced in prediabetes, screen-detected type 2 diabetes, and obesity and influenced by sex: the ADDITIONPRO Study," Diabetes, vol. 64, pp. 2513-2525, 2015.

[23] W. Creutzfeldt, R. Ebert, B. Willms, H. Frerichs, and J. C. Brown, "Gastric inhibitory polypeptide (GIP) and insulin in obesity: increased response to stimulation and defective feedback control of serum levels," Diabetologia, vol. 14, no. 1, pp. 15-24, 1978.

[24] T. Wikarek, J. Chudek, A. Owczarek, and M. OlszaneckaGlinianowicz, "Effect of dietary macronutrients on postprandial incretin hormone release and satiety in obese and normal-weight women," British Journal of Nutrition, vol. 111, no. 2, pp. 236-246, 2014.

[25] P. Hill, L. Garbaczewski, H. Koppeschaar, J. H. H. Thijssen, and F. d. Waard, "Glucagon and insulin response to meals in non-obese and obese Dutch women," Clinica Chimica Acta, vol. 165 , no. 2-3, pp. 253-261, 1987.

[26] A. Lund, T. Visbøll, J. I. Bagger, J. J. Holst, and F. K. Knop, "The separate and combined impact of the intestinal hormones, GIP, GLP-1, and GLP-2, on glucagon secretion in type 2 diabetes," American Journal of Physiology-Endocrinology and Metabolism, vol. 300, pp. 1038-1046, 2011.

[27] B. Ahrén, M. Landin-Olsson, P.-A. Jansson, M. Svensson, D. Holmes, and A. Schweizer, "Inhibition of dipeptidyl peptidase-4 reduces glycemia, sustains insulin levels, and reduces glucagon levels in type 2 diabetes," The Journal of Clinical Endocrinology \& Metabolism, vol. 89, no. 5, pp. 2078-2084, 2004.

[28] J. F. Carroll, K. A. Kaiser, S. F. Franks, C. Deere, and J. L. Caffrey, "Influence of BMI and gender on postprandial hormone responses $* *$." Obesity, vol. 15, no. 12, pp. 2974-2983, 2007.

[29] S. N. Davis, C. Shavers, and F. Costa, "Differential gender responses to hypoglycemia are due to alterations in CNS drive and not glycemic thresholds," American Journal of PhysiologyEndocrinology and Metabolism, vol. 279, no. 5, pp. E1054E1063, 2000.

[30] S. N. Davis, A. D. Cherrington, R. E Goldstein, J. Jacobs, and L. Price, "Effects of insulin on the counterregulatory response to equivalent hypoglycemia in normal females," American Journal of Physiology-Endocrinology and Metabolism, vol. 265, no. 5, pp. E680-E689, 1993.

[31] C. Fanelli, S. Pampanelli, L. Epifano et al., "Relative roles of insulin and hypoglycaemia on induction of neuroendocrine responses to, symptoms of, and deterioration of cognitive function in hypoglycaemia in male and female humans," Diabetologia, vol. 37, no. 8, pp. 797-807, 1994.

[32] P. Galassetti, D. Tate, R. A. Neill, S. Morrey, and S. N. Davis, "Effect of gender on counterregulatory responses to euglycemic exercise in type 1 diabetes," The Journal of Clinical Endocrinology \& Metabolism, vol. 87, no. 11, pp. 5144-5150, 2002.

[33] S. A. Amiel, A. Maran, J. K. Powrie, A. M. Umpleby, and I. A. Macdonald, "Gender differences in counterregulation to hypoglycaemia," Diabetologia, vol. 36 , no. 5, pp. 460-464, 1993.

[34] J. M. Rijkelijkhuizen, K. McQuarrie, C. J. Girman et al., "Effects of meal size and composition on incretin, $\alpha$-cell, and $\beta$-cell responses," Metabolism, vol. 59, no. 4, pp. 502-511, 2010. 